LBNL-53768

September 2003

\title{
Volatile Organic Chemical Emissions from Structural Insulated Panel (SIP) Materials and Implications for Indoor Air Quality
}

\author{
ALFRED T. HODGSON ${ }^{*}$ \\ Indoor Environment Department, Environmental Energy Technologies Division, E.O. Lawrence \\ Berkeley National Laboratory, Berkeley, CA, USA
}

\begin{abstract}
The emissions of volatile organic compounds (VOCs) from structural insulated panel (SIP) materials were investigated. Specimens of newly produced SIPs and associated panel adhesives were obtained from two relatively large manufacturers. Additionally, specimens of the oriented strand board (OSB) used as the inner and outer sheathing and the extruded polystyrene core for the SIP were obtained from one manufacturer. Using small-scale chambers, emissions of formaldehyde, acetaldehyde, acetic acid and other VOCs from SIPs, OSB and polystyrene were measured over a period of four months and from the adhesives over two months. SIP specimens overlaid by gypsum board panels were also tested over four months. The predominant VOCs emitted by the SIPs included acetic acid, pentanal, hexanal and styrene. The emissions of formaldehyde and acetaldehyde were relatively low. Acetic acid and the aldehydes derived from the OSB, while styrene derived from the polystyrene. One of the SIPs emitted toluene and methyl acetate. The adhesives primarily emitted a mixture of hydrocarbons. The emission rates of most VOCs from the SIP/gypsum board assemblies were approximately the same or higher than their respective emission rates from the unfinished SIPs.
\end{abstract}

Modeling using VOC emission factors obtained for the SIP/gypsum board assemblies demonstrated the potential for SIP materials to degrade indoor air quality in houses. A field study to investigate VOC concentrations and emission rates in SIP houses relative to closely

*Tel.: +1-510-486-5301. E-Mail: ATHodgson@lbl.gov 
matched conventionally constructed houses is necessary to determine the actual impacts of SIPs. If significant impacts are observed, to it may be desirable to develop control measures to reduce the emissions of VOCs from SIPs, such as the substitution of lower emitting materials or the use of vapor diffusion barriers.

\section{Introduction}

Structural insulated panels (SIPs) have been used in construction for many years. Although, SIPs currently hold only $\sim 0.05 \%$ of the new housing market in the U.S., they possess numerous advantages and are a promising alternative to traditional, wood frame, construction methods for

residential and small commercial structures. Specific benefits of SIPs relative to site-built frame construction include lower energy consumption, reduced job-site time and labor, stronger more durable structures and better resource efficiency.

SIPs are produced in a controlled factory environment and assembled at the building site. They combine load-bearing capacity and thermal insulation into a single unit. Typically, SIPs are constructed of a rigid plastic foam core sandwiched between exterior and interior sheathing. The foam core is most often extruded polystyrene. Sheathing is typically oriented strand board (OSB) bonded with adhesive to both sides of the foam core. The panels vary in size from 4-ft by 8-ft to large 8 -ft by $24-\mathrm{ft}$ assemblies. The panels are connected with mechanical fasteners and specially formulated adhesives. Approximately one large size adhesive tube (e.g., 29 oz) is used per 4-ft by 8-ft panel. In house construction, typically the entire exterior sidewalls are composed of SIPs. SIPs may also be used for floor and roof elements. Interior wall and ceiling surfaces are most often finished with gypsum board panels attached directly to the inner OSB skin. The resulting structure can have very low infiltration rates and a supplemental ventilation system may be required to achieve adequate outdoor air ventilation rates.

To the best of our knowledge, no detailed investigations of volatile organic pollutants in new SIP houses or other SIP structures have been performed. In fact, there is relatively little published data on the concentrations and emission rates of volatile organic compounds (VOCs) in new North American houses of any type. Much of the available data is from a research program at Lawrence Berkeley National Laboratory sponsored by the U.S. Department of Energy (Hodgson et al., 2000 and 2002). Recent results from that program for new manufactured and entry-level site built houses show that composite wood products such as 
particleboard, medium density fiberboard, hardboard and plywood are the predominant sources of formaldehyde and other VOCs including odorous compounds and sensory irritants. Since SIPs are constructed with an OSB composite wood interior skin and are most often finished with gypsum board, a material with high vapor permeability (Meininghaus et al., 2000; Meininghaus and Uhde, 2002), there exists a possibility that VOC emissions from the OSB may have measurable impacts on VOC concentrations in SIP structures. In addition, very large quantities of adhesives containing petroleum distillates are often used. Thus, it is prudent to examine the potential indoor air quality impacts of this construction technique.

The overall goals of this research program were to investigate the potential for contamination of indoor air due to the emissions of volatile organic compounds (VOCs) by different SIP systems and, if required, to develop strategies to minimize the impacts of these panel systems on indoor VOC concentrations. The specific objectives of the research reported on here were to 1) quantify the emissions of VOCs from specimens of larger production volume SIPs and associated adhesives representative of the predominant design employed by industry and 2) assess the extent to which these emissions might impact indoor air quality in residential structures constructed with SIPs.

\section{Materials and Methods}

\section{Collection of Material Samples}

Newly manufactured SIPs were obtained in March 2003 from two separate, relatively large, manufacturers, one located on the West Coast (manufacturer A) and one located on the East Coast (manufacturer B). In addition, the East Coast manufacturer provided new specimens of the OSB sheathing and the polystyrene core used to construct its panel. Manufacturer A supplied a full 4- by 8-ft panel, 6.625-in thick with 0.5-in thick OSB skins. It was transported by truck from the plant in Washington State to the laboratory. A colleague (S. Cox, Virginia Tech, VA) picked up the panel materials from manufacturer B in Virginia consisting of a full 4- by 8-ft panel, 4.625-in thick, a 4- by 8-ft panel of 0.5-in thick OSB and a 4- by 8-ft sheet of 3.625-in thick polystyrene. Within 24-h of collection, these were cut into 2- by 2-ft squares and wrapped in multiple layers of heavy-duty aluminum foil. Pieces then were shipped to the laboratory by airfreight. Containers (28 - $29 \mathrm{oz})$ of panel adhesive were obtained separately from both 
manufacturers. The VOC content listed on the container labels was 260 - 282 grams per liter, or approximately $20 \%$ by weight.

\section{Preparation of Test Specimens}

Test specimens were prepared in the laboratory upon receipt of the materials. First, 6.5- by 6.5-in (or 6- by 6-in) squares were cut from the SIPs at least 6-in away from the panel edges. These were sliced through the centers of their polystyrene cores to produce pieces one-half the thickness of the original panels. Boxes of stainless steel (SS) sheet metal were fabricated to enclose five sides of each specimen and leave only the face surface exposed. Cut sheet metal edges and the sheet metal box to material junction were carefully sealed with low-emitting aluminum tape $\left(\mathrm{Scotch}^{\mathrm{TM}}\right.$ Metal Repair Tape, 3M) leaving exposed surface areas of 0.0232 or $0.0195 \mathrm{~m}^{2}$. Two specimens were prepared from each manufacturer's panel. One specimen was unfinished with the OSB surface exposed. The other specimen was covered with a 0.5 -in thick gypsum board panel. For the manufacturer A specimen, the gypsum board panel was unpainted. For the manufacturer B specimen, the gypsum board panel had been painted previously with two coats of interior flat wall paint.

The polystyrene specimen was similarly prepared. A 6- by 6-in square piece was cut from the center of a supplied block. This was sliced through its center to produce a section one-half the thickness of the original and encased in a SS sheet metal box, leaving an exposed polystyrene surface area of $0.0195 \mathrm{~m}^{2}$.

A 6- by 6-in piece of OSB was cut from the center of a supplied piece. This was backed by SS sheet metal and its edges were sealed with aluminum tape so that only $0.0195 \mathrm{~m}^{2}$ of the OSB face was exposed. A bead of panel adhesive approximately 0.25 -in in diameter was applied with a caulking gun to a metal channel 0.25 -in wide, 0.125 -in high and 6-in long. The channel was weighed prior to and immediately following application to obtain the mass of wet adhesive.

The parameters for the study material specimens are given in Table 1.

\section{Testing of Specimens for VOC Emissions}

The emissions of VOCs and aldehydes from the test specimens were determined following the guidance of ASTM D-5116-97 (ASTM, 1997a). Immediately following preparation, a test specimen was transferred to a 10.5-L cylindrical chamber constructed of polished 316 stainless 
steel. This chamber was contained in an incubator operated at $23 \pm 1^{\circ} \mathrm{C}$. High-purity nitrogen at $0.059 \pm 0.003 \mathrm{~m}^{3} \mathrm{~h}^{-1}$ was split into two approximately equal streams. One of these was passed through a bubbler containing high-purity water. This was then mixed with the dry stream to produce a chamber humidity $50 \pm 5 \% \mathrm{RH}$. The initial samples for the analysis of VOCs and aldehydes were collected from the chamber exhaust at 96-h elapsed time. Each specimen was then transferred to a 19-L conditioning chamber supplied with charcoal filtered room air at approximately $0.06 \mathrm{~m}^{3} \mathrm{~h}^{-1}$. The conditioning chambers were held in a small temperatureconditioned room. Conditioning chamber temperatures and relative humidities were monitored with data loggers (HOBO H8, Onset Computer Corp.). The temperatures were approximately 23 $\pm 2^{\circ} \mathrm{C}$ and the humidities were approximately $50 \pm 10 \% \mathrm{RH}$.

Subsequent to the initial 96-h time point, the specimens were tested for VOC emissions at approximately 14, 30, 60 and 120 days, with the exception of the adhesives for which sampling was terminated at 60 days. For each test point, a material was transferred back to a $10.5-\mathrm{L}$ chamber and maintained at the original conditions for at least $48 \mathrm{~h}$ prior to the collection of VOC and aldehyde samples. The parameters used for conditioning and VOC emission measurements are summarized in Table 2.

\section{Diffusion Experiment}

An experiment was conducted to measure the diffusion of VOCs through gypsum board. An approximate $1-\mathrm{ft}^{2}$ piece of 0.625 -in thick OSB from manufacturer B was utilized as a VOC source. The OSB was placed on SS sheet metal inside an incubator operating at $23 \pm 1^{\circ} \mathrm{C}$. At time zero, a similar sized piece of new 0.5 -in thick, unpainted gypsum board was placed on the surface of the OSB, and a FLEC emission cell (Wolkoff et al., 1991) was positioned on top of the gypsum board. The FLEC was supplied with nitrogen gas flowing at $300 \mathrm{~cm}^{3} \mathrm{~min}^{-1}$ and humidified to approximately $50 \%$ RH. VOC samples were collected from the exit of the FLEC at five time points after initiating the experiment.

Sampling and Analysis of VOCs and Aldehydes

For the emission tests, duplicate VOC sampling tubes and a single aldehyde sampler were attached to a manifold on the exhaust of a small chamber. Sampling flow rates were controlled with mass flow controllers. The VOC sampling rates were typically $25-50 \mathrm{~cm}^{3} \mathrm{~min}^{-1}$ and the 
aldehyde sampling rate was $500 \mathrm{~cm}^{3} \mathrm{~min}^{-1}$. The VOC sample volumes were typically 0.75 - $1.5 \mathrm{~L}$; the aldehyde sample volume was $30 \mathrm{~L}$.

For the diffusion experiment, single VOC samples were collected from the FLEC at elapsed times of $0.5,1.5,3.0,19.3$ and $92.5 \mathrm{~h}$. The sampling flow rate was $100 \mathrm{~cm}^{3} \mathrm{~min}^{-1}$ for five minutes.

VOC gas samples were collected on Tenax-TA ${ }^{\mathrm{TM}}$ sorbent tubes (P/N CP-16251; Varian Inc.) modified by substituting a 15-mm section of Carbosieve S-III 60/80 mesh (P/N 10184, Supelco Inc.) at the outlet end. The VOC samples were analyzed by thermal desorption-gas chromatography/mass spectrometry generally following U.S. EPA Method TO-1 (U.S. EPA, 1984). The samples first were qualitatively examined. For this analysis, the VOCs emitted by each material were identified by comparison of the unknown spectra and their corresponding chromatographic retention times with spectra and retention times for pure compounds analyzed under the same conditions. In some cases, tentative or probable identifications were obtained based on matches with spectra in electronic libraries. Then, the samples were quantitatively analyzed for target compounds including odorous chemicals and chemicals of concern listed by U.S. EPA and/or California programs regulating and/or assessing health risks of toxic chemicals. For quantitative analysis, multi-point internal standard calibrations were created using pure compounds and 1-bromo-4-fluorobenzene as the reference compound. The relative precision of the sampling and analysis method for VOCs has been determined to be about $\pm 10 \%$ for most compounds (Hodgson, 2000). The lower limit of quantitation for a 1.5-L sample is about 1

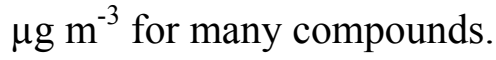

Samples for formaldehyde and acetaldehyde were collected on treated silica-gel cartridges (P/N WAT047205, Waters Corp.). The aldehyde samples were extracted with acetonitrile; the extracts were analyzed by high performance liquid chromatography with UV detection following ASTM standard method D-5197-97 (ASTM, 1997b). Multi-point calibrations were prepared for formaldehyde and acetaldehyde using their respective hydrazone derivatives. Relative precision is better than $\pm 10 \%$. The lower limit of quantitation for a $30-\mathrm{L}$ sample is about $1 \mu \mathrm{g} \mathrm{m}^{-3}$.

\section{Data Analysis}

Emission rates (ERs) of the target compounds in mass per time $\left(\mu \mathrm{g} \mathrm{h}^{-1}\right)$ were calculated assuming the chamber was an ideal continuously-stirred tank reactor (CSTR) operating at near 
steady-state conditions (ASTM, 1997a). Losses of compounds due to factors other than ventilation (e.g., as the result of net sink effects) were ignored. The steady-state form of the mass-balance model for CSTRs was used:

$$
E R=Q\left(C-C_{0}\right)
$$

where $\mathrm{Q}$ is the chamber inlet gas flow rate $\left(\mathrm{m}^{3} \mathrm{~h}^{-1}\right)$; $\mathrm{C}$ is the air concentration of the compound in the chamber $\left(\mu \mathrm{g} \mathrm{m}^{-3}\right)$; and $\mathrm{C}_{0}$ is the concentration of the compound in a blank chamber run $\left(\mu \mathrm{g} \mathrm{m}^{-3}\right)$.

Area-specific emission rates or emission factors (EFs) in mass per area-time $\left(\mu \mathrm{g} \mathrm{m}^{-2} \mathrm{~h}^{-1}\right)$ were calculated as:

$$
E F=\frac{Q\left(C-C_{O}\right)}{A}
$$

where A is the material's exposed surface area $\left(\mathrm{m}^{2}\right)$.

\section{Results}

\section{VOC Emissions from SIP Materials}

The VOCs emitted by the two unfinished SIPs (SIP-A and SIP-B from manufacturers A and $\mathrm{B}$, respectively) were qualitatively similar (Table 3 ). The predominant compounds were acetic acid, pentanal, hexanal, methyl acetate, toluene (SIP-A only), methyl acetate (SIP-A only), styrene and n-pentane. Most of the VOCs emitted by SIP-B were attributable to OSB-B used in its fabrication. The exceptions were styrene, isopropylbenzene, n-propylbenzene, 2-methylbutane and n-pentane, which derived from the polystyrene core.

Table 3 presents the VOC emission factors for the unfinished SIPs and SIP materials measured at one and four months. In this and subsequent tables, the compounds were grouped by chemical class and ordered by decreasing volatility within class. With the exception of phenol emitted by SIP-B and OSB-B, the emission factors of all quantified compounds declined over this period. Nevertheless, there still were substantial emissions of the predominant compounds at the four-month time point. The temporal emission profiles of four selected VOCs, acetic acid, acetaldehyde, hexanal and styrene, from the two unfinished SIPs and the SIP-B components are plotted in Figures 1-4, respectively. The emissions of all four compounds from 
the components (OSB-B or Polystyrene-B) were higher over the entire four-month period than the emissions of these compounds from SIP-B. The emissions of acetic acid from SIP-A were substantially higher over the four-month period than the emissions of this compound from both SIP-B and OSB-B. However, the emission profiles of acetaldehyde, hexanal and styrene were quite similar for the two SIPs. For each of these compounds, the difference at four months between the emission factors for the two panels was minor or negligible.

The emissions of four selected compounds, acetic acid, hexanal, toluene and styrene, from the unfinished and the gypsum-board covered SIPs are plotted and compared in Figures 5-8, respectively. For acetic acid, the emission factors for the unfinished panels initially exceeded the emission factors for the gypsum board covered panels. By 60 days, the acetic acid emission factors for treated and untreated panels were nearly similar. For the three remaining selected compounds, and most other compounds not shown in the figures, the emission factors for the gypsum board covered panels exceeded their respective emission factors from the unfinished panels. The differences between treated and untreated panels generally decreased with time, and at the four-month time period, they were small or negligible. Heterogeneity in initial VOC content between different sections of SIP panel is a possible explanation for this result. The two coats of flat latex paint on the gypsum board in the SIP-B assembly had no obvious effect on VOC emissions relative to results for the SIP-A assembly with unfinished gypsum board.

The VOCs emitted by the two panel adhesives (Adh-A and Adh-B from manufacturers A and $\mathrm{B}$, respectively) were qualitatively similar. Both adhesives emitted small amounts of acetic acid and complex mixtures of hydrocarbons mainly comprised of volatile $\mathrm{C}_{6}$ - $\mathrm{C}_{9}$ alkane hydrocarbons, alkyl substituted cyclohexanes, and $\mathrm{C}_{7}-\mathrm{C}_{8}$ aromatic hydrocarbons. Specimen Adh-A additionally emitted methylnaphthalene isomers. Emission rates normalized to the length of the adhesive bead (i.e., length-specific emission rates in $\mu \mathrm{g} \mathrm{m}^{-1} \mathrm{~h}^{-1}$ ) of selected VOCs measured at two weeks and two months are presented in Table 4. By two months, the emissions of most compounds had dropped substantially. Neither adhesive was a source of formaldehyde or acetaldehyde.

The results of the diffusion experiment are plotted in Figure 9. The three predominant VOCs, pentanal, hexanal and $\alpha$-pinene were quantified. At 30-min elapsed time, there were measurable emissions of all three compounds. In particular, the emission factor for a-pinene was 
nearly $400 \mu \mathrm{g} \mathrm{m}^{-2} \mathrm{~h}^{-1}$ at $30 \mathrm{~min}$. The maximum measured emissions of pentanal and a-pinene occurred at 90 minutes. The maximum measured value for hexanal occurred at 1,160 min (19.3 h). The emission factor for hexanal at 5,550 $\mathrm{min}(92.5 \mathrm{~h})$ was in good agreement with the 96-h hexanal emission factor for unfinished OSB (Figure 2). Acetic acid was not detected at quantifiable amounts in any of the samples.

\section{Discussion}

The measured VOC emissions from the SIPs and the OSB are largely consistent with values published in the literature for OSB and for plywood, a composite wood product also typically bonded with phenol-formaldehyde resin. However, OSB is distinct from the predominant southern pine plywood, as it typically is manufactured using hardwood stock. Emitted levels of monoterpenes, such as $\alpha$ - and $\beta$-pinenes and limonene are low, in hardwoods. Emitted levels of formaldehyde from phenol-formaldehyde OSB and plywood are substantially lower than emitted levels in urea-formaldehyde wood products (Kelly, 1996; Kelly et al., 1999). Barry and Corneau (1999) reported emission concentrations for a number of $\mathrm{C}_{1}-\mathrm{C}_{6}$ aldehydes and ketones produced by ten OSB panels after 24-h exposure in an environmental chamber. Most panels emitted very little formaldehyde and acetaldehyde. Pentanal and hexanal were the predominant aldehydes, with hexanal having the highest chamber concentrations. The area-specific emission rates of selected terpenes, aldehydes and acetic acid from softwood plywood were reported in two studies on new houses (Hodgson et al., 2000 and 2002). Here too, the emissions of formaldehyde and acetaldehyde were relatively low; the emissions of pentanal were elevated; and hexanal was the predominant emitted aldehyde. Acetic acid had the highest individual VOC emission rate (Hodgson et al., 2000).

It is likely that the toluene emitted by SIP-A did not derive from the OSB, as there have been no reports of emissions of aromatic hydrocarbon solvents from composite wood products. Styrene undoubtedly is a residual monomer in the polystyrene core. 2-Methylbutane and n-pentane likely are used as blowing agents in the production of polystyrene.

The rapid diffusion of nonpolar VOCs emitted by the OSB through the gypsum board layer and the approximately equal long-term VOC emission rates obtained for the unfinished and covered (i.e., overlaid with either virgin or painted gypsum board) SIP specimens are consistent 
with the results of other studies. Gypsum board is a highly porous building material. The rapid mass transport of relatively nonpolar VOCs through gypsum board has been demonstrated in several studies (Kirchner et al., 1999; Meininghaus et al., 2000; Tiffonnet et al., 2000; Meininghaus and Uhde, 2002). These studies used several methods to measure effective diffusion coefficients for the transport of n-octane and ethyl acetate through 0.5-in thick gypsum board. The values reported for n-octane were in the range of $6.7 \times 10^{-7}$ to $9.8 \times 10^{-7} \mathrm{~m}^{2} \mathrm{~s}^{-1}$; the values for ethyl acetate were in the range of $6.9 \times 10^{-7}$ to $1.2 \times 10^{-6} \mathrm{~m}^{2} \mathrm{~s}^{-1}$. The values for both n-octane and ethyl acetate are approximately one-tenth of the their respective diffusion rates in air. Meininghaus and Uhde (2002) investigated the diffusion of 20 VOCs through gypsum board. A number of these compounds reached steady-state conditions within several hours as evidenced by constant concentrations on both the source and measurement sides of the gypsum board specimen. This indicated that sorption of these compounds within the gypsum board was small. Less volatile and some more polar compounds exhibited a significant lag phase. The most polar compounds (e.g., 2-butoxyethanol, 2-phenoxy ethanol) were not detected on the measurement side within the approximate 30-h experimental period, demonstrating the effects of large sorption effects. Acetic acid exhibited the same behavior in the current study.

Indoor VOC concentrations resulting from the emissions of VOCs from an indoor material can be estimated by mass balance with Equation 2 given the quantity of the material installed in a house and the house parameters needed to determine outdoor air flow rate. In order to estimate the potential effects of the emissions of VOCs from SIPs, a small, rectangular-shaped, detached house with 1,290- $\mathrm{ft}^{2}\left(120-\mathrm{m}^{2}\right)$ floor area was hypothesized. The footprint dimensions were $48 \mathrm{x}$ $30 \mathrm{ft}$ with a $10 \times 15$-ft entry porch at one corner. A cathedral ceiling with a 1:4 pitch, window area equal to $12 \%$ of the side wall area, and two standard exterior doors were assumed. SIP materials in the form of 4-ft wide panels were used for the sidewalls and the floor. The interior surfaces of the sidewalls were finished with 0.5-in painted gypsum board. Carpet covering 75\% of the floor represented the fraction of SIP floor area exposed to the interior volume. In total, there was approximately $2,200 \mathrm{ft}^{2}\left(200 \mathrm{~m}^{2}\right)$ of SIP effectively exposed to an interior volume of $1,270 \mathrm{ft}^{3}\left(360 \mathrm{~m}^{3}\right)$. An ASHRAE minimum ventilation rate of $0.35 \mathrm{~h}^{-1}$ was assumed (ASHRAE, 1999). Indoor concentrations in ppb for the house were modeled using VOC emission factors measured at four months for the SIPs overlaid with gypsum board and the VOC emission factors of $\mathrm{m} / \mathrm{p}$-xylene measured at two months for the adhesives. The estimated concentrations for each 
manufacturer's products are shown in Table 5. The estimated concentrations of acetic acid, pentanal, hexanal, phenol, toluene, $\mathrm{m} / \mathrm{p}$-xylene and styrene approach or exceed their respective maximum concentrations measured in recent studies of indoor VOC concentrations for new U.S. single-family residences (Lindstrom et al., 1995; Hodgson et al., 2000) as summarized by Hodgson and Levin (2003).

An in-depth evaluation of the potential health and comfort effects of the emissions of VOCs from SIPs is beyond the scope of this report. However, the predicted indoor concentrations of several of the VOCs associated with SIP materials are of potential concern. The odor of acetic acid can be detected at very low concentration. The 100\% odor detection threshold for acetic acid is $10 \mathrm{ppb}$ (Cometto-Muñiz et al., 1998). Fifty percent odor detection thresholds (a more commonly reported number) are approximately one-order of magnitude lower (i.e, $\sim 1 \mathrm{ppb}$ ) (Cometto-Muñiz, 2000). Acetic acid also is a sensory irritant at relatively low concentration. The time-weighted average Threshold Limit Value (TLV) for industrial exposures to acetic acid is $10 \mathrm{ppm}$ based on irritation as the effect (ACGIH, 2000). A downward scaling factor for estimating the effect for the general population is often considered to be in the range of $10-40$ (Alaire et al., 2000; Nielsen et al., 1995). Use of a scaling factor of this magnitude suggests that an appropriate indoor guideline concentration for acetic acid to protect against irritation may be $250-1,000 \mathrm{ppb}$. Neilsen et al. (1998) set an indoor guideline for sensory irritation at 1,000 ppb for acetic acid. Hexanal is another highly odorous compound. The odor threshold for hexanal, summarized from the literature, is 14 ppb (Devos et al., 1990). This value is consistent with the more recently reported $100 \%$ odor detection threshold for hexanal scaled for $50 \%$ detection (Cometto-Muñiz et al., 1998). Chronic exposures to toluene affect the nervous and respiratory systems. Both the Agency for Toxic Substances and Disease Registry and the Cal-EPA Office of Environmental Health Hazard Assessment have recommended 80 ppb as an acceptable concentration for chronic exposure of the general population, including sensitive individuals, to toluene (ASTDR, 2003; Cal/EPA, 2002). Styrene is considered a possible human carcinogen (IARC, 1994).

\section{Conclusions}

SIP materials are relatively strong sources of several VOCs, including acetic acid, pentanal, hexanal, toluene (one manufacturer), and styrene. The emissions of acetic acid and the 
aldehydes are attributable to the OSB used as the outer layers of the SIP assembly. Styrene derives from the polystyrene core. SIP adhesives, which are used in large quantity in SIP construction, are sources of aromatic, cyclic and alkane hydrocarbons. There were similarities in the VOC emissions characteristics of the two SIPs studied. The exceptions were acetic acid, which was emitted at higher rates from one SIP, and toluene, which only was emitted by the same individual SIP.

Due the highly permeable character of gypsum board, which is the most common interior finish material, VOC emitted from SIPs used to construct walls and ceilings of houses will enter indoor air at rates largely unaffected by the presence of gypsum board. Previous studies also have shown that carpet and carpet cushion do not reduce the emissions of VOCs from underlying composite wood flooring materials (Hodgson et al., 2002). Thus, houses constructed of SIPs can be expected to have elevated concentrations of certain VOCs.

The potential for SIPs to impact indoor air quality was demonstrated by a modeling exercise for a small hypothetical house. Estimated concentrations for the modeled house constructed with SIPs approached or exceeded maximum concentrations measured in new houses. The modeled concentrations of several of the VOCs emitted by SIPs are of potential concern with respect to comfort and health of residential occupants. Concentrations of acetic acid and hexanal may exceed their respective odor thresholds. Such odors may persist for long periods, affecting occupants' satisfaction with indoor air quality. Acetic acid is a relatively potent sensory irritant with an effect level likely below $1 \mathrm{ppm}$. Toluene is predicted to have noncancer chronic effects at relatively low concentrations.

The model results need to be confirmed by a field study of SIP houses. Since there are numerous potential sources of the compounds of concern, an opportunity should be sought to conduct a controlled study in which VOC concentrations and emission rates in several newly constructed SIP houses are compared to values in conventional houses, closely matched with respect to age, size, interior finishes, furnishings and occupancy.

The development of source control measures for SIPs to reduce their emissions of VOCs into indoor air may be warranted, particularly if SIP houses are shown to have relatively high VOC concentrations. Potentially effective measures include the substitution of the inner OSB skin with a lower emitting and possibly less permeable material and the introduction of a diffusion 
barrier between the OSB and the gypsum board interior finish material. In developing such strategies, humidity control and the transport of water vapor through the wall assembly should be considered.

\section{Acknowledgements}

The author thanks Tosh Hotchi and Diane Ivy of LBNL for assistance in the laboratory, Steve Cox of VT for collection of material, and Terry Logee, the program manager, for his support. This work was supported by the Assistant Secretary for Energy Efficiency and Renewable Energy, Building Technology Program of the U.S. Department of Energy (DOE) under contract No. DE-AC03-76SF00098.

\section{References}

ATSDR. 2003. Minimal Risk Levels (MRLs) for Hazardous Substances. Atlanta GA, Agency for Toxic Substances and Disease Registry. ATSDR web site http://www.atsdr.cec.gov/mrls.html.

Alarie Y, Nielsen GD and Schaper MM. 2000. Animal bioassays for evaluation of indoor air quality. In Indoor Air Quality Handbook, Spengler JD, Samet JM and McCarthy JF (Eds.). McGraw-Hill, New York, NY, pp. 23.1-23.49.

ACGIH. 2000. $2000 T L V s^{\circledR}$ and BEIs ${ }^{\circledR}$, Threshold Limit Values for chemical substances and physical agents and Biological Exposure Indices, Cincinnati OH, American Conference of Governmental Industrial Hygienists.

ASHRAE. 1999. Ventilation for acceptable indoor air quality, Atlanta GA, American Society of Heating, Refrigerating, and Air Conditioning Engineers, Inc. (ASHRAE Standard 62-1999).

ASTM. 1997a. Standard Guide for Small-Scale Environmental Chamber Determinations of Organic Emissions from Indoor Materials/Products, West Conshohocken, PA, American Society for Testing and Materials (ASTM Standard D 5116-97).

ASTM. 1997b. Standard Test Method for Determination of Formaldehyde and Other Carbonyl Compounds in Air (Active Sampler Methodology). West Conshohocken, PA, American Society for Testing and Materials (ASTM Standard D 5197-97.

Cal-EPA. 2002. Air Toxics "Hot Spots" Program Risk Assessment Guidelines. Part III. Technical Support Document for the Determination of Chronic Reference Exposures Levels for Airborne Toxicants. Office of Environmental Health Hazard Assessment, Air Toxicology and Epidemiology Section, California Environmental Protection Agency, Berkeley, CA. CalEPA Air Toxics Hot Spots web site: http://www.oehha.org/air/chronic_rels/.

Cometto-Muñiz, JE. 2000. Physicochemical basis for odor and irritation potency of VOCs. In Indoor Air Quality Handbook, Spengler JD, Samet JM and McCarthy JF (Eds.). McGrawHill, New York, NY, pp. 20.1-20.21. 
Cometto-Muñiz JE, Cain WS and Abraham MH. 1998. Nasal pungency and odor of homologous aldehydes and carboxylic acids. Exp. Brain Res. 118: 180-188.

Devos M, Patte, F, Rouault J, Laffort P and van Gemert LJ (Eds.). 1990. Standardized Human Olfactory Thresholds. IRL Press, Oxford, England.

Hodgson AT, Beal D and McIlvaine JER. 2002. Sources of formaldehyde, other aldehydes and terpenes in a new manufactured house. Indoor Air 12: 1-8.

Hodgson AT and Levin H. 2003. Volatile organic compounds in indoor air: a review of concentrations measured in North America since 1990. Report LBNL-51715, Lawrence Berkeley National Laboratory, Berkeley, CA.

Hodgson AT, Rudd AF, Beal D and Chandra S. 2000. Volatile organic compound concentrations and emission rates in new manufactured and site-built houses. Indoor Air 10: 178-192.

IARC, 1994. Monographs on the Evaluation of the Carcinogenic Risk of Chemicals to Man. Geneva: World Health Organization, International Agency for Research on Cancer, 1972Present (Multi-volume work). p. 60297.

Kelly TJ. 1996. Determination of formaldehyde and toluene diisocyanate emissions from indoor residential sources, Final Report Contract No. 93-315, California EPA, Air Resources Board, Sacramento, CA.

Kelly TJ, Smith DL and Satola J. 1999. Emission rates of formaldehyde from materials and consumer products found in California Homes, Environ. Sci. Technol. 33: 81-88.

Kirchner S, Badey JR, Knudsen HN, Meininghaus R, Quenard D, Saarela K, Sallee H and Saarinen A. 1999. Sorption capacities and diffusion coefficients of indoor surface materials exposed to VOCs: proposal of new test procedures. In Raw G, Aizlewood C and Warren P (eds.) Indoor Air '99. Proceedings of the $8^{\text {th }}$ International Conference on Indoor Air Quality and Climate. Edinburgh, Scotland, Vol. 1, pp. 430-435.

Lindstrom AB, Proffitt D and Fortune CR. 1995. Effects of modified residential construction on indoor air quality. Indoor Air 5: 258-269.

Meininghaus R and Uhde E. 2002. Diffusion studies of VOC mixtures in a building material. Indoor Air 12: 215-222.

Meininghaus R, Gunnarsen L and Knudsen HN. 2000. Diffusion and sorption of volatile organic compounds in building materials - Impact on indoor air quality. Environ. Sci. Technol. 34: 3101-3108.

Nielsen GD, Alarie Y, Poulsen OM and Nexø BA. 1995. Possible mechanisms for the respiratory tract effects of noncarcinogenic indoor-climate pollutants and bases for their risk assessment. Scand. J. Work Environ. Health 21: 165-178.

Nielsen GD, Hansen LF, Nexø BA and Poulsen OM. 1998. Indoor air guideline levels for formic, acetic, propionic and butyric acid. Indoor Air Suppl. 5: 8-24.

Tiffonnet AL, Blondeau P and Allard F. 2000. Assessment of contaminant diffusivities in building materials from porosity tests. In Seppänen, $\mathrm{O}$ and Säteri J (eds.) Healthy Buildings 2000. Proceedings, Espoo, Finland, Vol. 4, pp. 199-204. 
U.S. EPA. 1984. Method TO-1, Revision 1.0: Method For The Determination Of Volatile Organic Compounds in Ambient Air Using Tenax ${ }^{\circledR}$ Adsorption and Gas Chromatography/Mass Spectrometry (GC/MS), Center for Environmental Research Information, Office of Research and Development, United States Environmental Protection Agency.

Wolkoff P, Clausen PA, Nielsen PA, Gustafsson H, Jonsson B and Rasmusen E. 1991. Field and Laboratory Emission Cell: FLEC. Indoor Air 1: 160-165. 
Table 1. Description of study material specimens.

\begin{tabular}{|c|c|c|c|}
\hline Material ID & Manuf $^{a}$ & $\begin{array}{r}\text { Exposed } \\
\text { Area }\left(\mathrm{m}^{2}\right) \\
\end{array}$ & Specimen Description \\
\hline SIP & A & 0.0232 & $\begin{array}{l}\text { 16.8-cm thick SIP cut in half to } 8.4-\mathrm{cm} \\
\text { thickness; boxed in SS sheet metal }\end{array}$ \\
\hline SIP & B & 0.0195 & $\begin{array}{l}11.8-\mathrm{cm} \text { thick SIP cut in half to } 5.9-\mathrm{cm} \\
\text { thickness; boxed in SS sheet metal }\end{array}$ \\
\hline SIP w/ GB & A & 0.0232 & $\begin{array}{l}\text { Same dimensions as SIP-A; overlaid with } \\
1.27 \text {-cm thick, unpainted gypsum board; } \\
\text { boxed in SS sheet metal }\end{array}$ \\
\hline $\mathrm{SIP}$ w/ GB & B & 0.0195 & $\begin{array}{l}\text { Same dimensions as SIP-B; overlaid with } \\
1.27 \text {-cm thick, painted gypsum board; } \\
\text { boxed in SS sheet metal }\end{array}$ \\
\hline OSB & B & 0.0195 & $\begin{array}{l}1.27-\mathrm{cm} \text { thick oriented stand board used in } \\
\text { production of SIP-B; backed with SS } \\
\text { sheet metal; edges sealed with Al tape }\end{array}$ \\
\hline Polystr & B & 0.0195 & $\begin{array}{l}\text { 9.2-cm thick, extruded polystyrene core } \\
\text { used in production of SIP-B; cut in half } \\
\text { to } 4.6 \text {-cm thickness; boxed in SS sheet } \\
\text { metal }\end{array}$ \\
\hline Adh & A & $0.152^{\mathrm{b}}$ & $\begin{array}{l}\text { 0.64-diameter bead of panel adhesive } \\
\text { applied in meal channel; } 6.0 \mathrm{~g} \text { wet } \\
\text { weight }\end{array}$ \\
\hline Adh & B & $0.152^{\mathbf{b}}$ & $\begin{array}{l}\text { 0.64-diameter bead of panel adhesive } \\
\text { applied in meal channel; } 5.5 \mathrm{~g} \text { wet } \\
\text { weight }\end{array}$ \\
\hline
\end{tabular}

a. Manufacturer identifier

b. Length of adhesive bead in meters 
Table 2. Parameters for conditioning and testing material specimens for emissions of VOCs using small-volume chambers.

\begin{tabular}{|l|c|c|}
\hline Parameter & Units & Value \\
\hline Conditioning Period & & \\
Temperature & ${ }^{\circ} \mathrm{C}$ & $21 \pm 2$ \\
Relative humidity & $\% \mathrm{RH}$ & Ambient \\
Volume & $\mathrm{m}^{3}$ & 0.019 \\
Flow rate & $\mathrm{m}^{3} \mathrm{~h}^{-1}$ & $0.066 \pm 0.010$ \\
Test Period & & \\
Temperature & ${ }^{\circ} \mathrm{C}$ & $23 \pm 1$ \\
Relative Humidity & $\% \mathrm{RH}^{3}$ & $50 \pm 5$ \\
Volume & $\mathrm{m}^{3}$ & 0.0105 \\
Flow rate & $\mathrm{m}^{3} \mathrm{~h}^{-1}$ & $0.059 \pm 0.003$ \\
Ventilation rate & $\mathrm{h}^{-1}$ & 5.66 \\
Specimen area & $\mathrm{m}^{2}$ & $\sim 0.02$ \\
Loading ratio & $\mathrm{m}^{2} \mathrm{~m}^{-3}$ & $\sim 2$ \\
Area/Flow rate ratio & $\mathrm{m}^{2} / \mathrm{m}^{3} \mathrm{~h}^{-1}$ & $\sim 0.35$ \\
\hline
\end{tabular}


Table 3. Emission factors $\left(\mu \mathrm{g} \mathrm{m}^{-2} \mathrm{~h}^{-1}\right)$ of predominant VOCs measured at one and four months for SIP specimens from manufacturers A and B (SIP-A and SIP-B) and OSB and polystyrene specimens from manufacturer B (OSB-B and Polystr-B).

\begin{tabular}{|c|c|c|c|c|c|c|c|c|c|}
\hline \multirow[b]{3}{*}{ Compound } & \multirow{3}{*}{$\begin{array}{l}\text { Chem } \\
\text { Class }\end{array}$} & \multicolumn{8}{|c|}{ Emission Factor $\left(\mu \mathrm{g} \mathrm{m}^{-2} \mathrm{~h}^{-1}\right)$} \\
\hline & & \multicolumn{2}{|c|}{ SIP-A } & \multicolumn{2}{|c|}{ SIP-B } & \multicolumn{2}{|c|}{ OSB-B } & \multicolumn{2}{|c|}{ Polystyr-B } \\
\hline & & $1 \mathrm{mon}$ & 4 mon & $1 \mathrm{mon}$ & 4 mon & $1 \mathrm{mon}$ & 4 mon & $1 \mathrm{mon}$ & 4 mon \\
\hline Acetic acid & Acid & $\mathrm{md}^{\mathrm{a}}$ & 1,620 & 410 & 320 & 1,080 & 700 & & \\
\hline 2-Hexanoic acid & Acid & $++^{\mathbf{b}}$ & + & + & + & + & + & & \\
\hline Formaldehyde & Ald & & & 4.8 & $<3$ & $<3$ & & & \\
\hline Acetaldehyde & Ald & 8.9 & 3.7 & 5.8 & $<3$ & 22 & 7.4 & & \\
\hline Pentanal & Ald & 30 & 16.3 & 28 & 17.1 & 74 & 15.4 & & \\
\hline Hexanal & Ald & 111 & 79 & 100 & 68 & 340 & 101 & & \\
\hline Methyl acetate & Estr & 149 & 55.2 & 13.1 & 4.7 & 64 & 24 & & \\
\hline 1-Pentanol & Alc & 16.6 & $<3$ & 13.4 & 11.5 & 56 & 13.2 & & \\
\hline Phenol & Alc & 8.9 & 5.6 & 12.8 & 20 & 12.0 & 18.2 & & \\
\hline Toluene & Aro & 210 & 120 & & & & & & \\
\hline Styrene & Aro & 26 & 24 & 32 & 25 & & & 96 & 43 \\
\hline Isopropylbenzene & Aro & & & 5.9 & 3.4 & & & 9.3 & 3.7 \\
\hline n-Propylbenzene & Aro & & & $<3$ & $<3$ & & & 4.7 & $<3$ \\
\hline 2-Methylbutane & Alk & + & + & + & + & & & + & + \\
\hline n-Pentane & Alk & 210 & 14.1 & 340 & 11.8 & & & 300 & 4.2 \\
\hline
\end{tabular}
a. $\quad \mathrm{md}=$ Missing data
b. $\quad+=$ Present, but not quantified 
Table 4. Length-specific emission rates $\left(\mu \mathrm{g} \mathrm{m}^{-1} \mathrm{~h}^{-1}\right)$ of selected VOCs measured at two weeks and two months for panel adhesive specimens from manufacturers A and B (Adh-A and Adh-B).

\begin{tabular}{|c|c|c|c|c|c|}
\hline \multirow[b]{3}{*}{ Compound } & \multirow[b]{3}{*}{ Class } & \multicolumn{4}{|c|}{ Length-Specific Emission Rate $\left(\mu \mathrm{g} \mathrm{m}^{-1} \mathrm{~h}^{-1}\right.$} \\
\hline & & \multicolumn{2}{|c|}{ Adh-A } & \multicolumn{2}{|c|}{ Adh-B } \\
\hline & & $2 \mathrm{wk}$ & 2 mon & $2 \mathrm{wk}$ & $2 \mathrm{mon}$ \\
\hline Acetic acid & Acid & 6.8 & 10.6 & 11.5 & 12.4 \\
\hline Toluene & Aro & 2.5 & $<1$ & $<1$ & $<1$ \\
\hline Ethylbenzene & Aro & 1.9 & $<1$ & $<1$ & $<1$ \\
\hline $\mathrm{m} / \mathrm{p}$-Xylene & Aro & 7.4 & 2.5 & 4.4 & 1.3 \\
\hline o-Xylene & Aro & 2.0 & $<1$ & 1.3 & $<1$ \\
\hline 2-Methylnaphthalene & Aro & 3.9 & 2.2 & & \\
\hline 1-Methylnaphthalene & Aro & 1.5 & $<1$ & & \\
\hline Methylcyclohexane & Cycl & 11.1 & 5.1 & 12.0 & 4.4 \\
\hline n-Hexane & Alk & 8.6 & 1.3 & 21 & 3.0 \\
\hline n-Heptane & Alk & 11.6 & 2.8 & 4.9 & 1.3 \\
\hline n-Octane & Alk & 5.1 & 2.0 & 2.2 & 1.2 \\
\hline n-Nonane & Alk & 6.0 & 2.9 & 1.1 & $<1$ \\
\hline
\end{tabular}


Table 5. Modeled indoor concentrations (ppb) of target VOCs in a hypothetical 1,290 $\mathrm{ft}^{2}$ house constructed using either manufacturer A or B SIP panels and adhesives for sidewalls and floors. Also shown are geometric mean (GM) and maximum (Max) indoor concentrations of the selected VOCs from two studies of new U.S. houses.

\begin{tabular}{|lc|cc|cc|}
\hline & & \multicolumn{4}{|c|}{ Concentration (ppb) $^{*}$} \\
\cline { 3 - 6 } Compound & Chem. & \multicolumn{2}{|c|}{$\begin{array}{c}\text { Modeled } \\
\text { Manuf. A }\end{array}$} & $\begin{array}{c}\text { Manuf. B } \\
\text { Measured }^{\mathbf{b}}\end{array}$ & \multicolumn{2}{|c|}{ New Houses (n=17) } \\
Class & House & House & GM & Max \\
\hline Acetic acid & Acid & 1,380 & 210 & 71 & 280 \\
Formaldehyde & Ald & $<1$ & 7.5 & 32 & 62 \\
Acetaldehyde & Ald & 3.1 & 5.6 & 14 & 43 \\
Pentanal & Ald & 7.2 & 9.0 & 2.5 & 9.8 \\
Hexanal & Ald & 38 & 34 & 15 & 36 \\
Phenol & Alc & $<1$ & 6.3 & 1.8 & 5.8 \\
Toluene & Aro & 52 & $-\mathbf{c}^{\mathbf{c}}$ & 8.5 & 68 \\
m/p-Xylene & Aro & $2.5^{\mathbf{d}}$ & $1.2^{\mathbf{d}}$ & 2.1 & 11 \\
Styrene & Aro & 11.9 & 12.6 & 0.6 & 7.8 \\
\hline
\end{tabular}

a. Based on VOC Emission factors measured at four months for SIPs overlaid with gypsum board. The ventilation rate was assumed to $0.35 \mathrm{~h}^{-1}$. See text for complete description of house parameters

b. Summarized by Hodgson and Levin, 2003

c. No toluene predicted to be present from SIP materials

d. Based on VOC emissions from SIP adhesives measured at two months and an assumed bead length of $540 \mathrm{~m}$ (i.e., one-half the total amount of adhesive used to assemble 74 SIPs) 


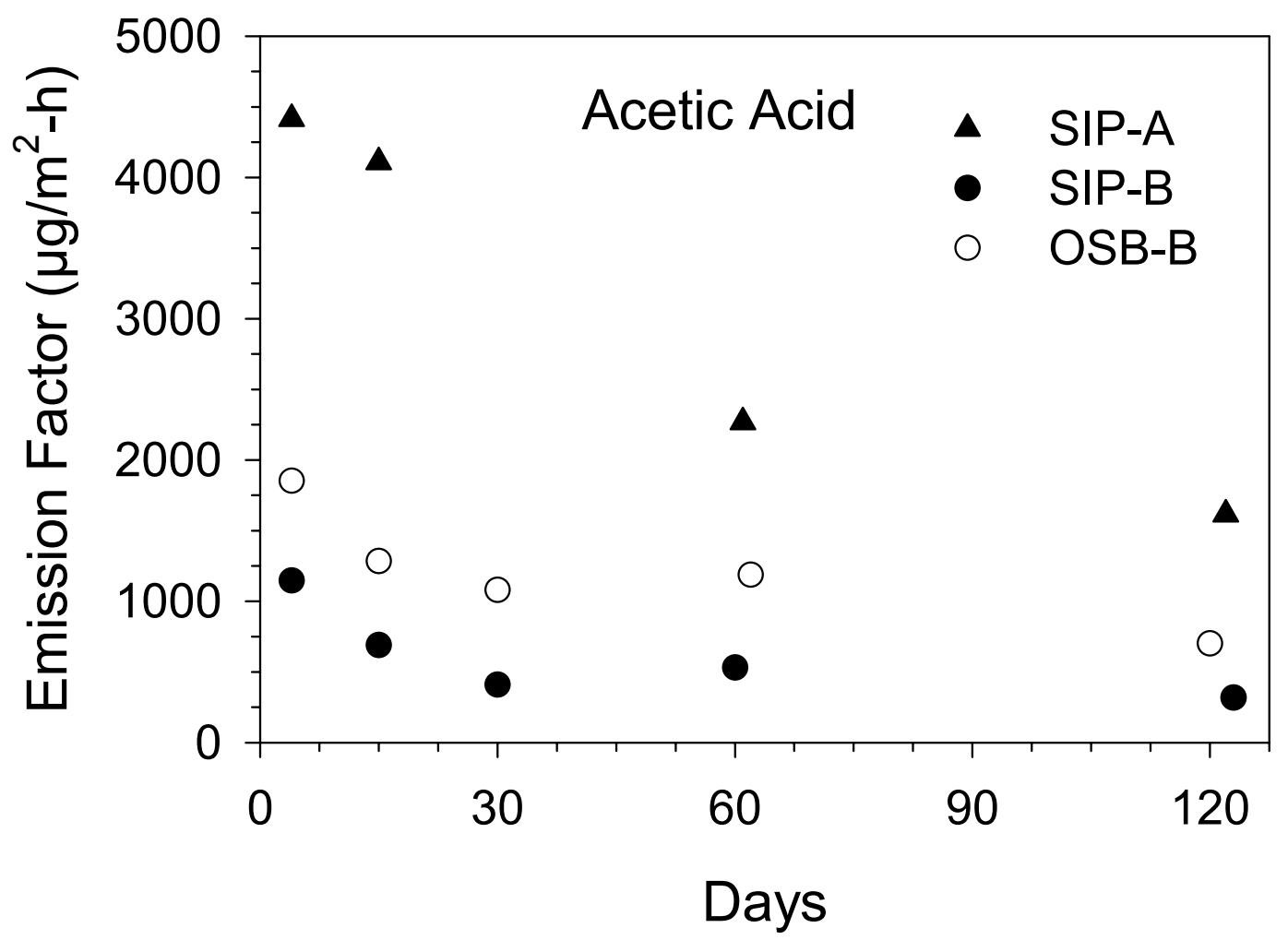

Figure 1. Acetic acid emission factors measured over a four-month period for materials SIP-A, SIP-B and OSB-B. 


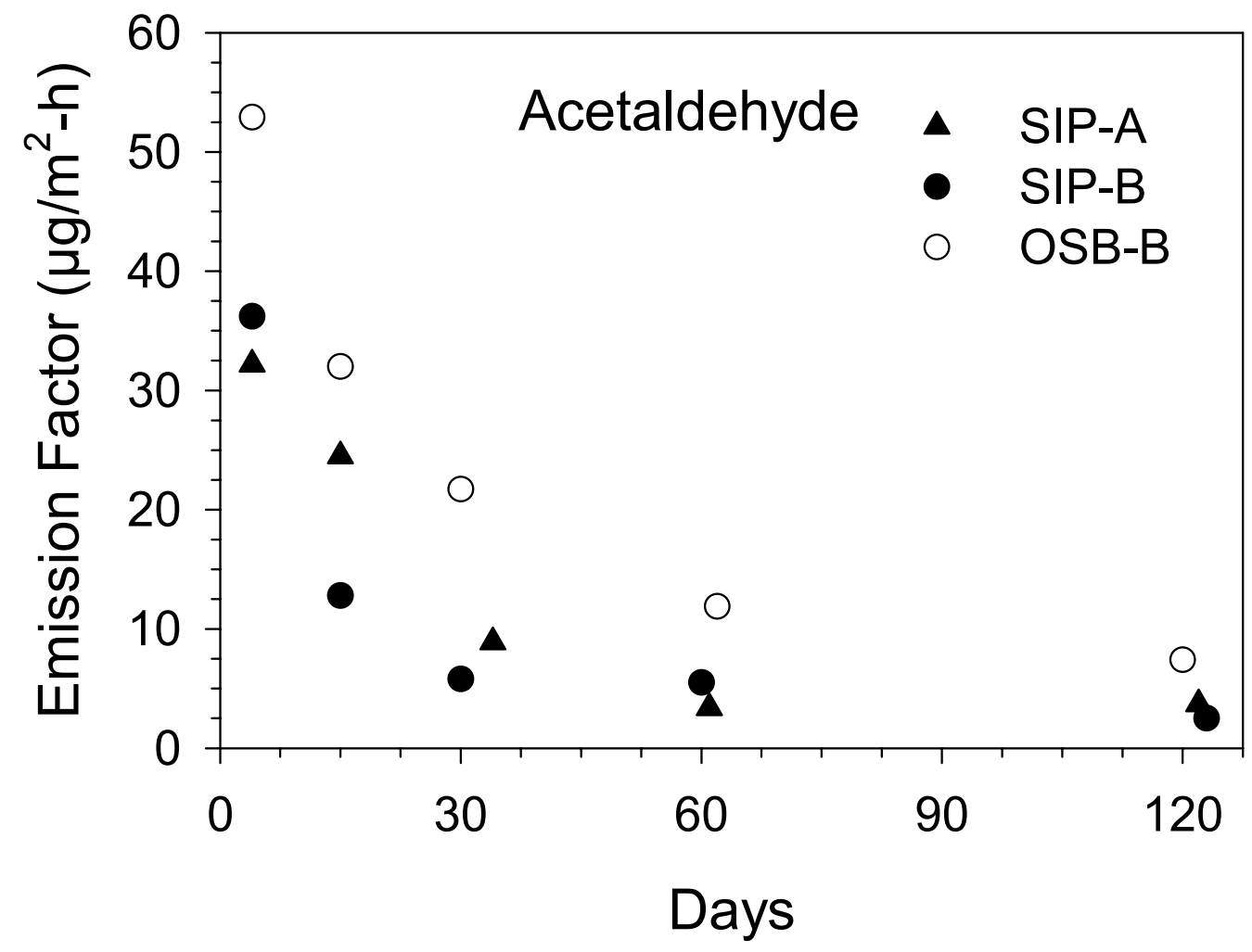

Figure 2. Acetaldehyde emission factors measured over a four-month period for materials SIP-A, SIP-B and OSB-B. 


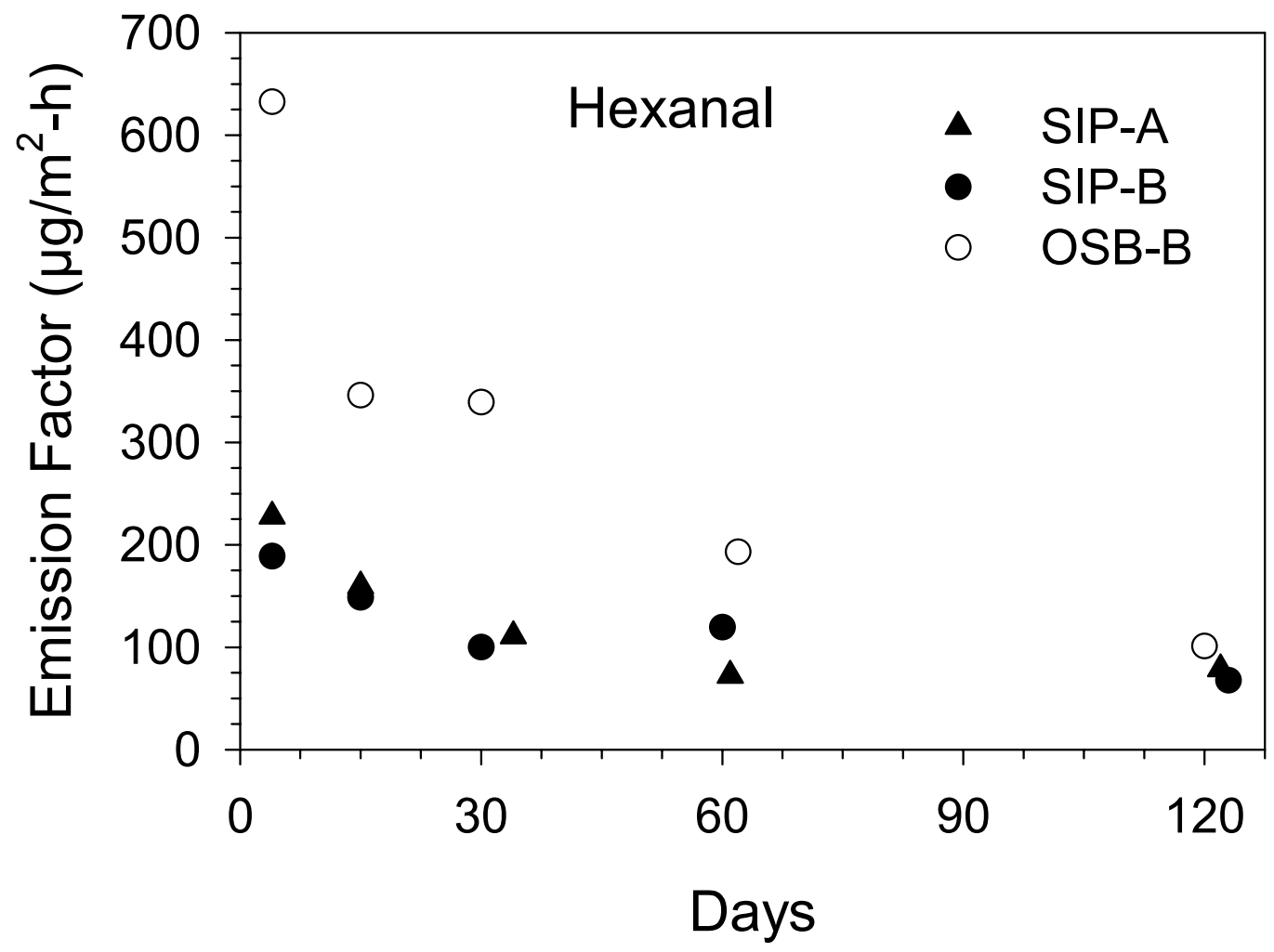

Figure 3. Hexanal emission factors measured over a four-month period for materials SIP-A, SIP-B and OSB-B. 


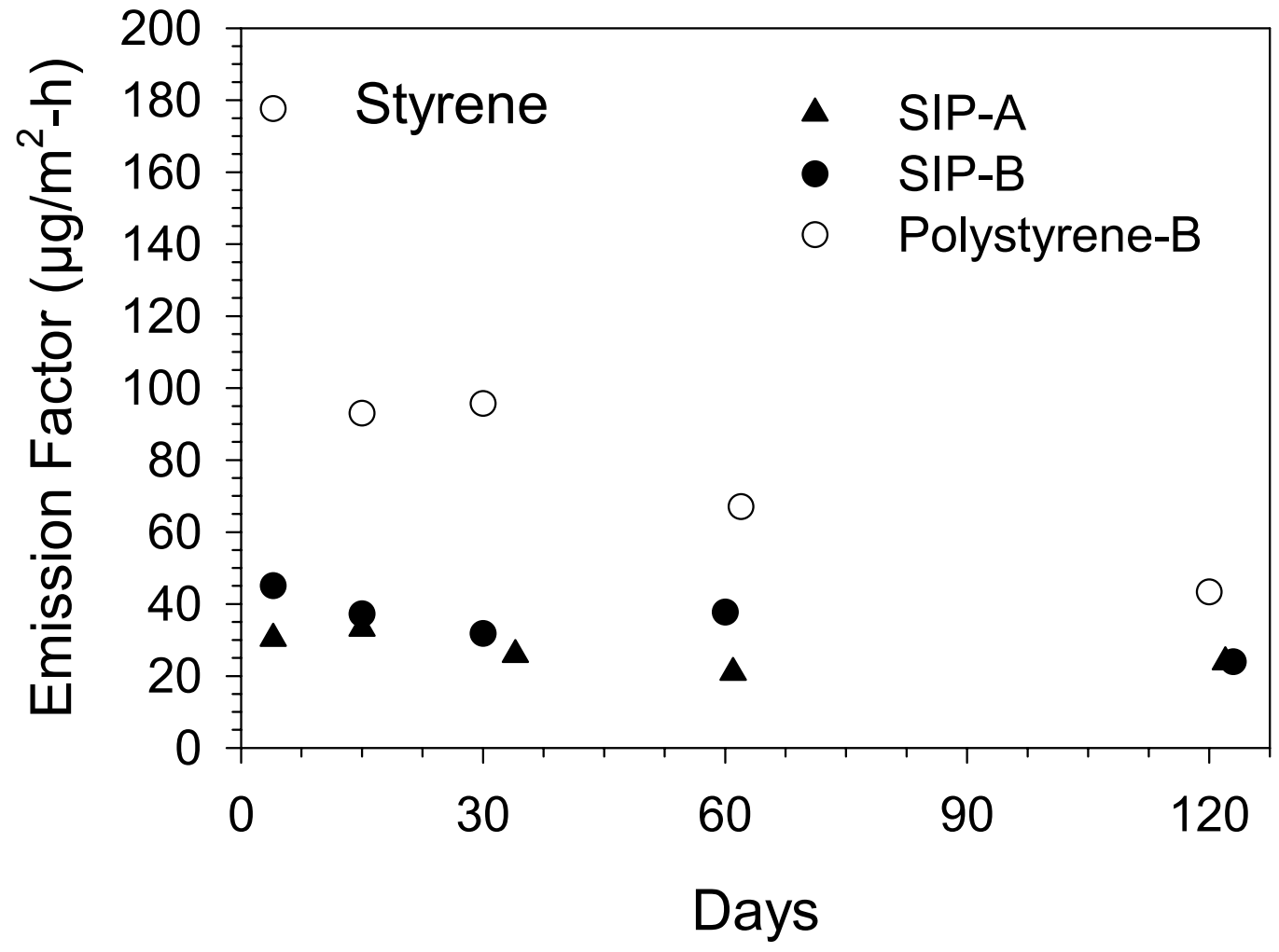

Figure 4. Styrene emission factors measured over a four-month period for materials SIP-A, SIP-B and Polystyrene-B. 


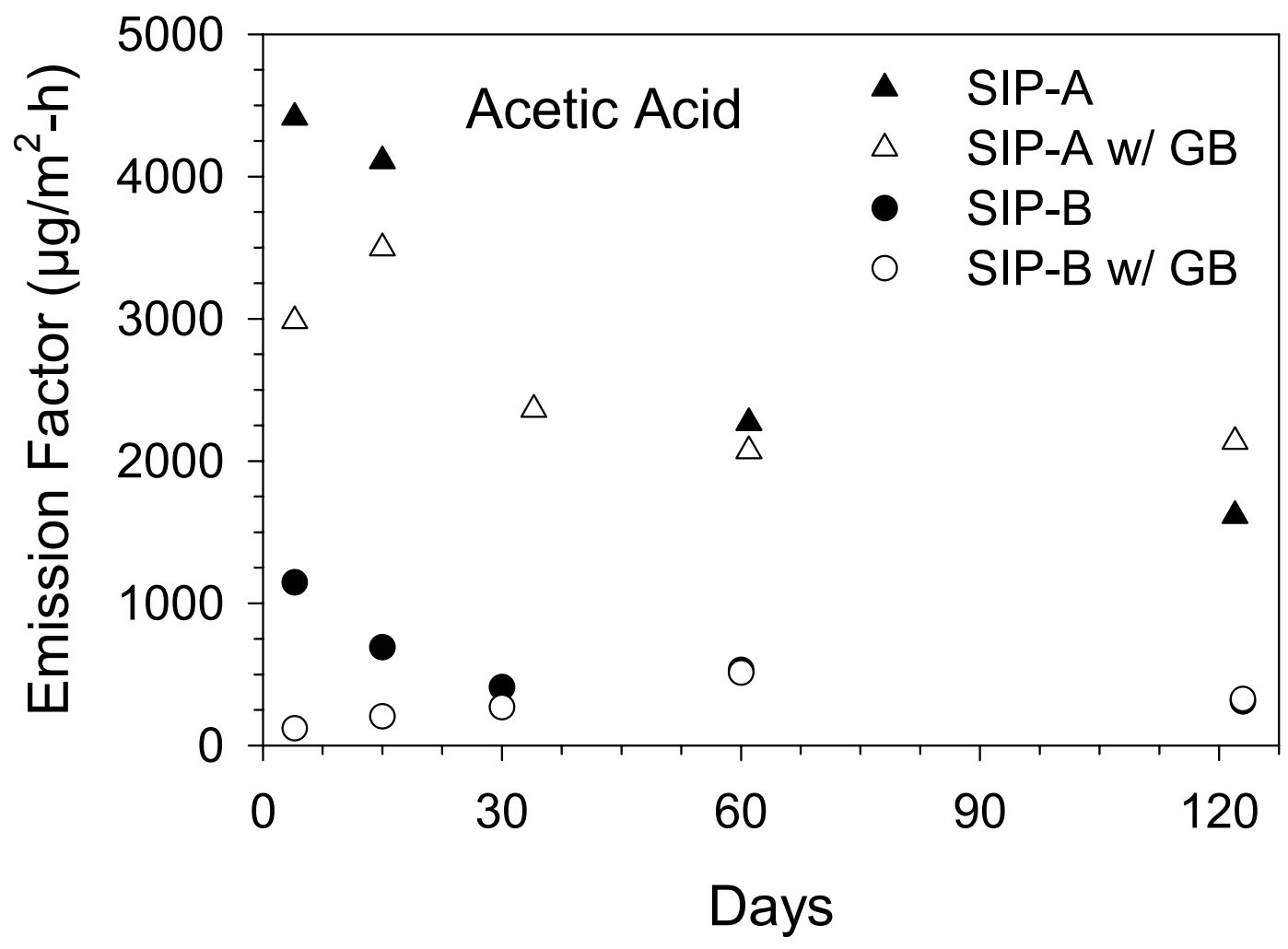

Figure 5. Acetic acid emission factors measured over a four-month period for materials SIP-A and SIP-B exposed with and without an overlay of 0.5-in thick gypsum board (GB). 


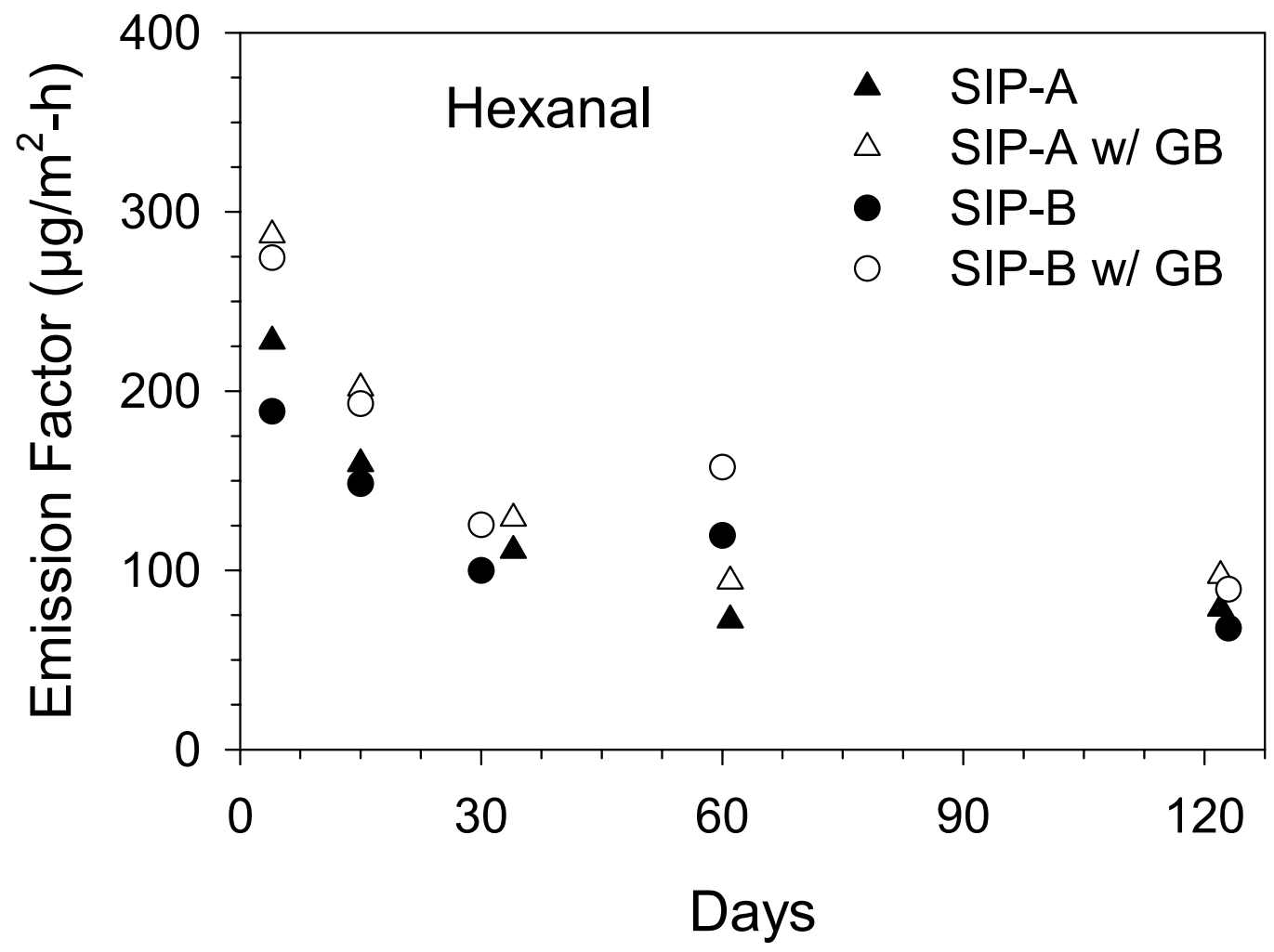

Figure 6. Hexanal emission factors measured over a four-month period for materials SIP-A and SIP-B exposed with and without an overlay of 0.5 -in thick gypsum board (GB). 


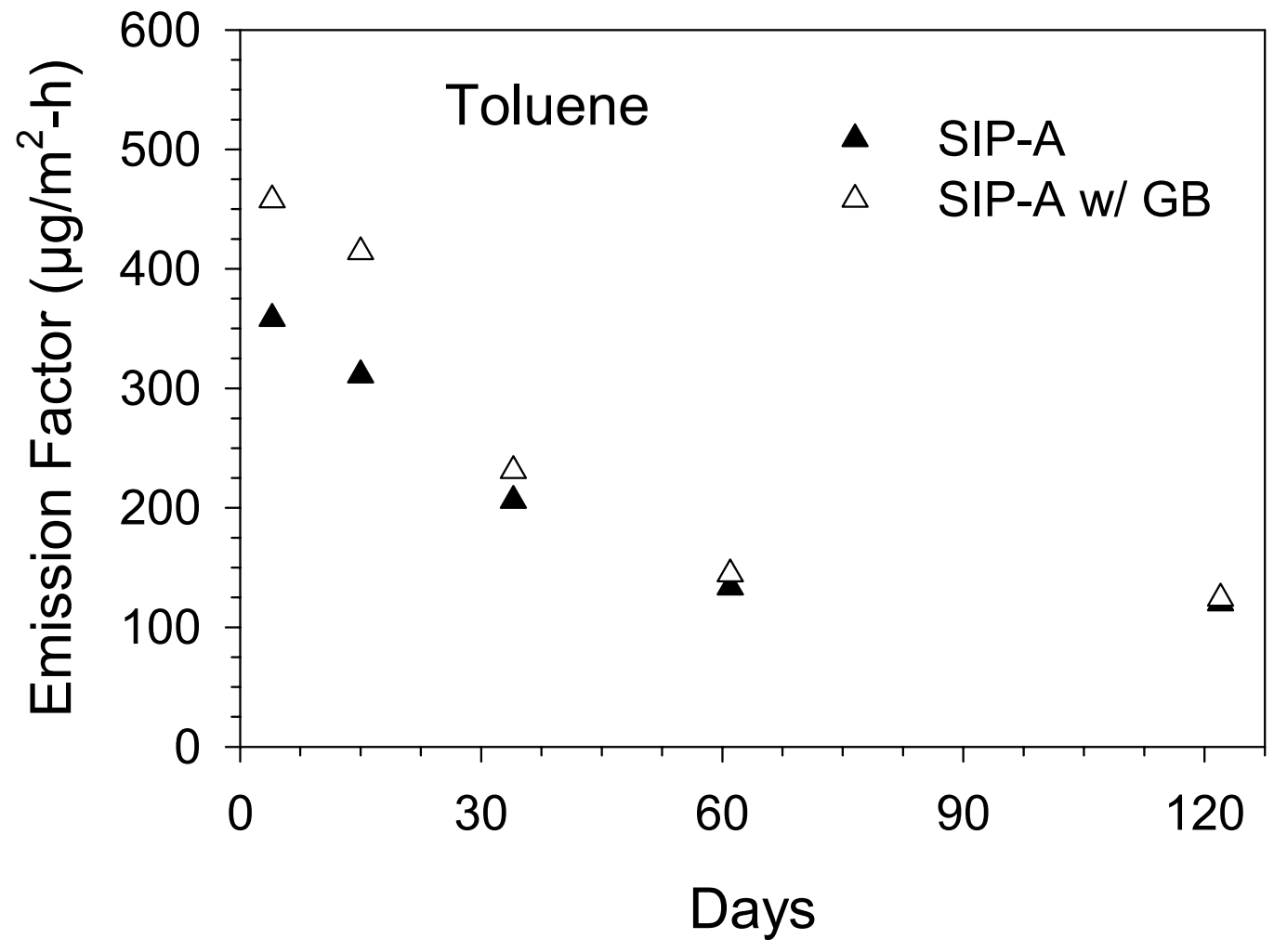

Figure 7. Toluene emission factors measured over a four-month period for material SIP-A exposed with and without an overlay of 0.5 -in thick gypsum board (GB). 


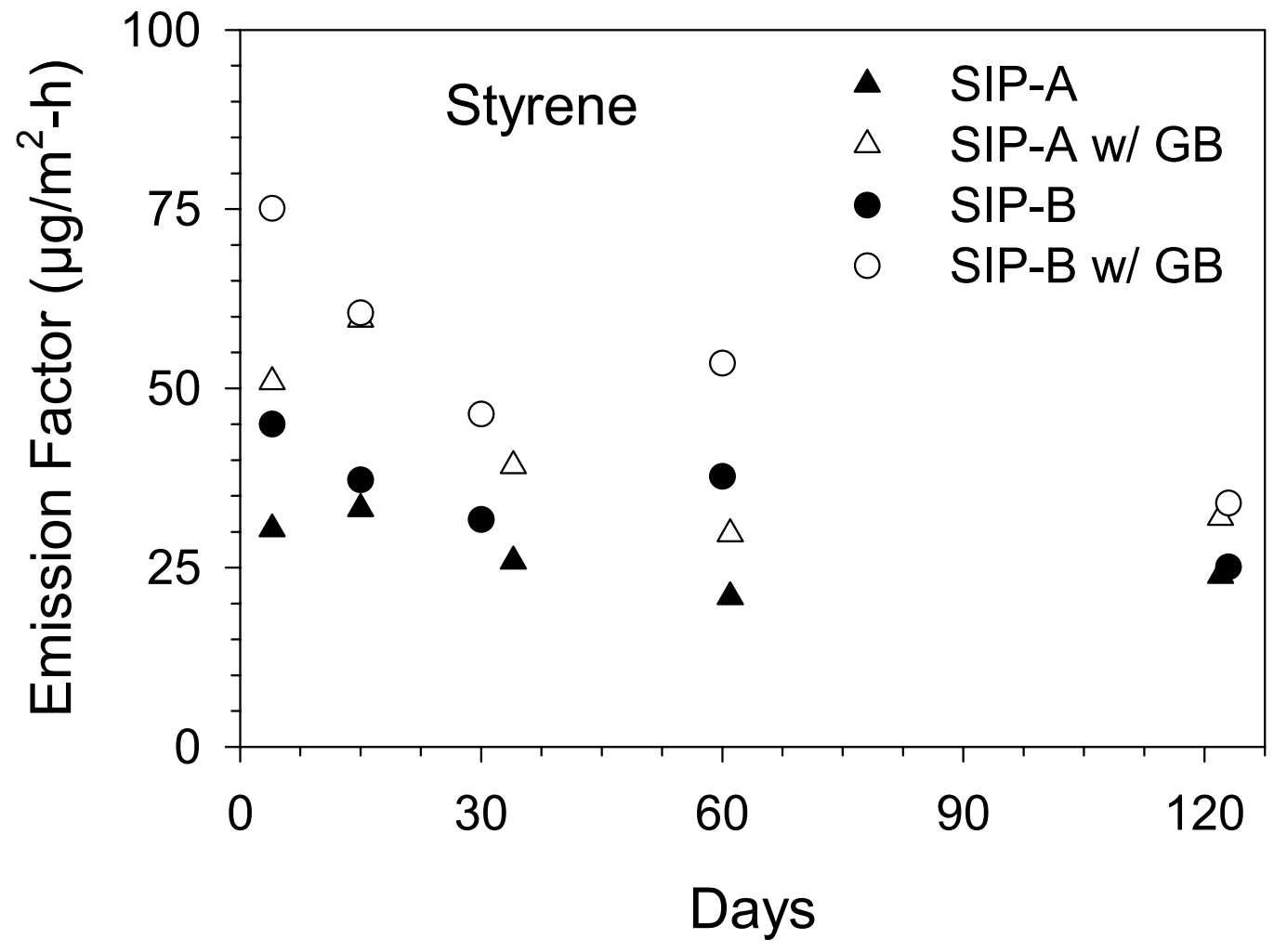

Figure 8. Styrene emission factors measured over a four-month period for materials SIP-A and SIP-B exposed with and without an overlay of 0.5-in thick gypsum board (GB). 


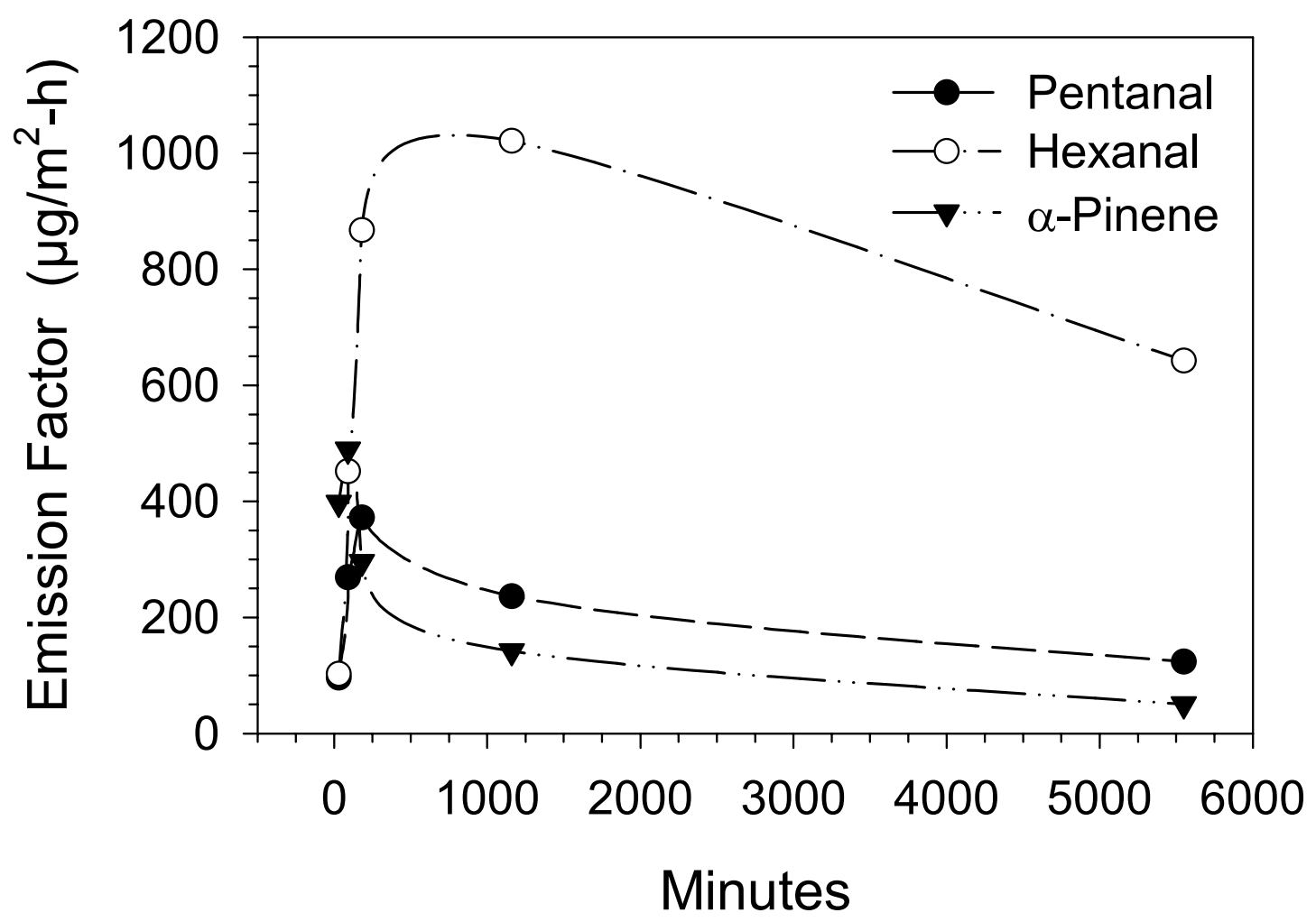

Figure 9. Emission factors of three VOCs evolved over time from an assembly of 0.5 -in thick OSB overlaid by 0.5 -in thick, unpainted gypsum board panel. Creation of the assembly and placement of the FLEC on the gypsum board surface established time zero. 
